\title{
Atividades de observação do comportamento de Sotalia guianensis como subsídio para o Turismo Científico no Parque Estadual Ilha do Cardoso - Cananeia (SP)
}

\section{Marcelo Nivert Schlindwein, Andreia Tami Akaki, Natasha Marcili Laganaro}

\section{RESUMO}

A espécie Sotalia guianensis, boto-cinza, pertence à subordem Odontoceti, que inclui todos os cetáceos com dentes e compõe a maior subordem dentro do grupo. Pertence a família Delphindae e possui uma ampla distribuição, indo desde costa leste da América Central (Honduras, Nicarágua, Panamá) à costa leste da América do Sul (Colômbia, Venezuela, Guiana, Suriname e Brasil), ocorrendo em baías, enseadas e desembocaduras de rios. Pode ser considerada uma espécie-bandeira para conservação, sendo carismática e de importância chave para o ecossistema no qual ocorre, podendo ter grande influência no que diz respeito a elaboração de projetos de conservação. Dentre as ações necessárias a isso está o Ecoturismo vinculado com o Turismo Científico, que pode vir a complementar os esforços na busca pela reparação dos danos causados ao meio ambiente por ação antrópica. Neste, a conscientização alcança um grau emocional, capaz de envolver o ser humano em seu meio natural. A área escolhida para estudo comportamental do boto-cinza foi o Parque Estadual da Ilha do Cardoso, uma importante área representativa de cobertura de Mata Atlântica, restinga e manguezal em termos de biodiversidade do complexo estuarino lagunar de Cananeia-lguapeParanaguá. As metodologias empregadas foram: scan ou focal, que consiste na observação a partir de pontos fixos na praia; transecto com estilo específico, na qual os comportamentos são observados no decorrer de uma caminhada; transecto dentro da água, na qual é percorrido o percurso dentro da água, na altura do joelho; registro temporal binário, com permanência de 10 minutos na areia, sem anotar qualquer tipo de comportamento e 5 minutos dentro do mar anotando os comportamentos observados ; formação de barreira na água, formando um semi-círculo na água, tendo a maioria dos integrantes, água na altura da cintura. Como principais comportamentos observados está o comportamento de deslocamento e de pesca, além de saltos, comportamento de reconhecimento e brincadeiras. As metodologias que apresentaram um maior número de comportamentos observados foi o scan ou focal e a formação de barreira na água, sendo essa última a mais indicada para prática de Ecoturismo por garantir uma maior proximidade com os botos cinzas e experiências marcantes decorrentes disso. A prática dessas atividades mostrou-se extremamente válida para conservação da espécie, uma vez que é capaz de estimular a criação de uma consciência ecológica através de uma atividade turística, criando teorias quanto o grau de influência da presença humana na vida de outros seres.

PALAVRAS-CHAVE: Conservação; Ecoturismo; Sotalia guianensis. 
Atividades de observação do comportamento de Sotalia guianensis como subsídio para o Turismo Científico no Parque Estadual Ilha do Cardoso - Cananeia (SP).

\section{Activity of observation the behavior of Sotalia guianensis as support for Scientific Tourism in the Parque Estadual da IIha do Cardoso (Cananeia, SP, Brazil)}

\section{ABSTRACT}

The specie Sotalia guianensis, estuarine dolphin, bolongs to the suborder Odontoceti, which includes all cetaceans with teeth and composes the largest suborder within the group. Belongs to family Delphindae and has a wide distribution, ranging from the East coast of Central America (Honduras, Nicaragua, Panama) to the East cost of South America (Colombia, Venezuela, Guyana, Suriname and Brazil), occurring in coves, bays and mouths of rivers. Can be considered a species-flag for conservation, being charismatic and key importance to the ecosystem in with it occurs and may have great influence on the development of conservation projects. Among the actions necessary to this is the ecotourism linked with scientific tourism that could complement efforts in the quest for compensation for damage caused to the environment by human action. In this, the emotional awareness reaches a degree, capable of involving the human in this natural environment. The area chosen for behavioral study of dolphin was the Parque Estadual Ilha do Cardoso, an important area representative coverage of Mata Atlântica, resting and mangrove in terms of biodiversity of the lagoon complex of Cananeia-Iguape-Paranaguá. The methodologies employed were: scan or focal, which consists of note from fixed point on the beach; transect with specific style, in which behaviors are observed during a walk; transect into the water, in which the route is covered in water, at the knee height; temporal binary registry with permanence 10 minutes in the sand, without annotate any type of behavior and 5 minutes inside the sea noting the behaviors observed; formation of barrier in water, forming a semi-circle in the water, with most members, water at waist height. As major behaviors observed is the displacement behavior and fishing, beyond jumps, behavior recognition and banter. The methodologies that showed a greater number of behaviors observed was the scan or focal and barrier formation in water, beings this last more likely to practice of ecological tourism by ensuring greater proximity with porpoises ash and remarkable experiences arising thereof. The practice of these activities proved extremely valid for conservation of the species, since it is capable of stimulate the creation an ecological awareness through a tourism activity, creating theories about the degree of human presence influence in the lives of other species.

KEYWORDS: Conservation; Ecotourism; Sotalia guianensis.

\section{Introdução}

Os Cetáceos (do grego ketos, que significa monstro marinho), compreendem cerca de 79 espécies vivas (PALAZZO; BOTH, 1988; SOUZA, 2010), abrangendo as baleias, botos e golfinhos, sendo a maioria das espécies e gêneros exclusivamente marinhos. Possui uma distribuição geográfica global, ocorrendo em todos os oceanos e em algumas bacias fluviais. São divididos em três subordens: 1) Archaeoceti, que inclui todas as espécies de cetáceos extintos; 2) Mysticeti, que inclui todas as baleias de grande porte, que apresentam placas de barbatanas ao invés de dentes e; 3) Odontoceti, inclui todos os cetáceos que possuem dentes, cerca de 67 espécies, sendo a maior subordem dentro do grupo (NARDY, 2003; MOTTA, 2006; SOUZA, 2010). 
As principais características morfológicas deste grupo são: corpo fusiforme (em formato hidrodinâmico) e desaparecimento do pescoço. Para que estes mamíferos retornassem a vida exclusivamente aquática, algumas adaptações foram necessárias, como: membros anteriores transformados em nadadeiras e regressão dos posteriores; possuem nadadeira ou aleta caudal; desenvolvimento de espessa camada de gordura (principalmente para isolamento térmico); deslocamento do orifício respiratório para cima da cabeça; desenvolvimento de um sistema de ecolocação (NARDY, 2003).

O boto cinza (Sotalia guianensis) (Fig. 1), pertence a família Delphindae dentro da subordem dos Odontoceti; possui um comprimento médio de 1,7 $\pm 0,2 \mathrm{~m}$, sendo que o maior registro para machos é de $2 \mathrm{~m}$ e para fêmeas é de 2,06 m (CREMER, 2000; MONTEIRO et al., 2006).

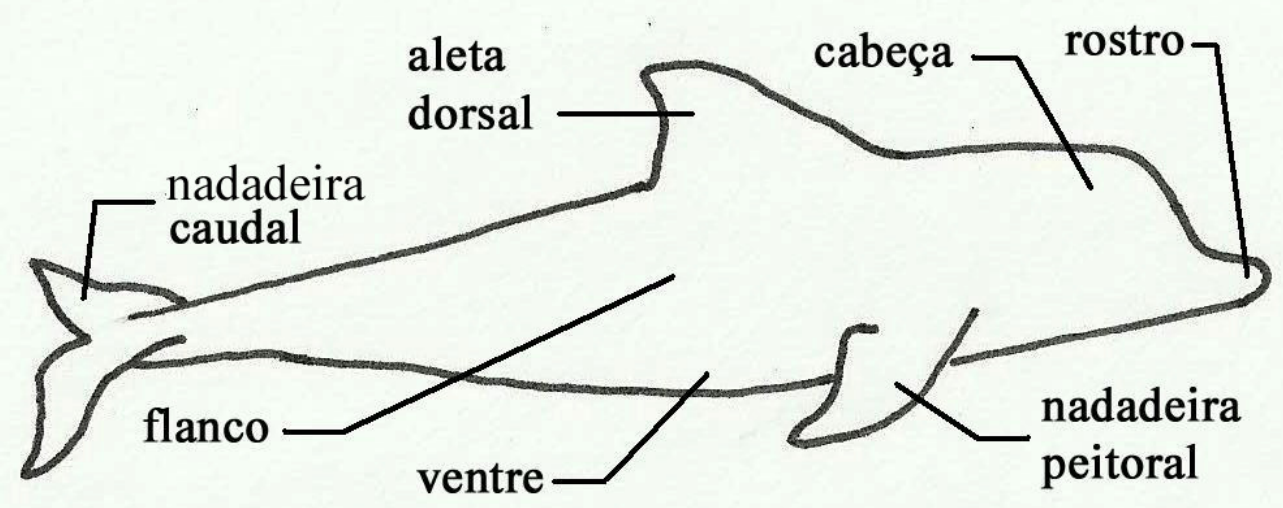

Figura 1 - Morfologia externa do boto cinza (Sotalia guianensis). Desenho: AKAKI, A. T.

Esta espécie possui uma ampla distribuição, que vai da costa leste da América Central (Honduras, Nicarágua, Panamá) à costa leste da América do Sul (Colômbia, Venezuela Guiana Suriname e Brasil) (CREMER, 2000; MONTEIRO-FILHO et al., 2008). Sendo assim a distribuição é considerada contínua ao longo da costa, ocorrendo em baías, enseadas e desembocaduras de rios. Apesar da espécie ser considerada costeira, foi registrada no Arquipélago de Abrolhos, a $70 \mathrm{~km}$ do litoral da Bahia, em uma área de Alargamento da Plataforma Continental (CREMER, 2000).

O boto-cinza é considerado espécie-bandeira, uma vez que são classificadas como espécies carismáticas e a pressão de uso turístico destas pode levar a programas de conservação do ambiente, tornando-se um elemento fundamental para profissionais da área da Biologia da Conservação na elaboração de planos de manejo para conservação da diversidade (SCHILINDWEIN, 2009). Além disso, as espéciesbandeira podem ajudar a aumentar a consciência da comunidade sobre a seriedade dos problemas e das questões ambientais da região (GIRAUDO; POVEDANO, 2005). 
Atividades de observação do comportamento de Sotalia guianensis como subsídio para o Turismo Científico no Parque Estadual Ilha do Cardoso - Cananeia (SP).

No passado, muito da perda da diversidade marinha foi ignorado, porque havia o conceito de que os recursos dos oceanos são infindáveis, porém, hoje, sabe-se que várias espécies marinhas estão reconhecidamente declinando, sendo que a documentação sobre as extinções destas está apenas começando (HERO; HIGWAY, 2006).

Sendo assim, estabelecer prioridades de conservação tem se tornado necessário e por vezes até urgente, diante da alta velocidade de degradação dos recursos naturais. A ecologia, a biologia da conservação e o turismo científico tem sido as ciências que se propõe a ajudar na busca de soluções para problemas ambientais, como o de estabelecimento de prioridades para conservação (SCARANO, 2006).

A ciência que damos o nome de Turismo pode ser entendida, segundo Moesch (2000 apud SCHILINDWEIN, 2009, p. 20) como

uma combinação complexa de inter-relacionamentos entre produção e serviços, em cuja composição integram-se uma prática social com base cultural, com herança histórica, a um meio ambiente diverso, cartografia natural, relações sociais de hospitalidade, troca de informações inter culturais. O somatório dessa dinâmica sócio cultural gera um fenômeno, recheado de objetividade / subjetividade, consumido por milhões de pessoas, como sintese: O produto turístico.

O turismo, portanto, abarca uma série de elementos que afetam as relações do homem com o ambiente. $O$ uso da diversidade para fins turísticos pode levar uma forte pressão social para a preservação e manutenção de espaços naturais considerados atrativos para o homem e transformados em monumentos naturais (SCHILINDWEIN, 2009).

Sendo assim, os cientistas têm desempenhado um papel crucial na estabilização e na promoção de visitação de áreas naturais e protegidas, uma vez que o ecoturismo está estritamente relacionado com o turismo científico. Esta observação é reforçada, já que para obter bons resultados no gerenciamento do ecoturismo, é necessário que sua gestão esteja bem suprida de informações, considerando importante para isto, a implementação de programas de projetos de pesquisa, que por sua vez venham gerar dados relevantes para gestão de recursos locais, garantindo seu uso sustentável dos mesmos (MAMEDE; ALHO, 2003).

Ou seja, o turismo científico busca despertar nas pessoas a necessidade de preservação ambiental, que acontece através de visitas, estadas ou viagens a lugares geográficos onde a natureza oferece possibilidades para conhecer mais de perto tudo que for relacionado às ciências naturais, com o objetivo de estudar e apreciar a fauna e a flora local (VELOSO, 2003; ROSINI; FERREYROS, 2005)

Dessa forma, o objetivo do estudo que gerou este artigo seria definir dentre as 
metodologias de estudo comportamental a que melhor se adequaria a uma atividade que pudesse servir de subsídio para a implantação do turismo científico, ou seja, que proporcionaria a visualização de um número maior de comportamentos, atrelados a uma maior interação entre o ser humano, no caso os turistas, e o boto-cinza. Isso porque que a espécie é considerada extremamente carismática na região do Parque Estadual da Ilha do Cardoso, uma Unidade de Conservação frequentada por muitos turistas diante das belezas naturais que o lugar oferece. Sendo assim, é interessante o uso desta espécie-chave para proporcionar um maior contato aos turistas com a natureza selvagem e encantá-los e sensibilizá-los, a fim de os tornarem colaboradores dos programas de conservação.

\section{Descrição da Área de Estudo}

O Parque Estadual da llha do Cardoso (PEIC) é uma Unidade de Conservação de Proteção Integral e foi criado em 1962 pelo Decreto Estadual 40.319 (SOS - MATA ATLÂNTICA, 2003; CAMPOLIM et al., 2008). Possui uma área de $151 \mathrm{~km}^{2}$ e é administrado pelo Instituto Florestal da Secretaria do Meio Ambiente do Estado de São Paulo (SOS MATA ATLÂNTICA , 2003; WIECZOREK, 2006).

O complexo de llhas onde está inserido o Parque é uma das mais importantes áreas de conservação do Brasil, uma vez que possui a mais representativa cobertura de Mata Atlântica, restinga e manguezal em termos de biodiversidade do complexo estuarino lagunar de Cananéia-Iguape-Paranaguá. Além da conexão com a Reserva Biológica Juréia-Itains e com o Parque Jacupiranga e do Petar, a região da llha do Cardoso é um dos principais elementos da formação Lagamar, um dos mais significativos estuários do Atlântico Sul; abrigando animais silvestres ameaçados em extinção ou em perigo, como: jacaré-do-papo-amarelo, suçuarana, anta, jacutinga, e papagaio-de-cara-roxa. As áreas do Parque também são utilizadas como local de descanso ou alimentação durante deslocamentos e migração de diversas espécies (SOS Mata Atlântica, 2003).

\section{Metodologia}

Para o estudo comportamental da espécie $S$. guianensis e posterior definição da melhor metodologia que possa ser empregada em futuras atividades de turismo científico, os estudantes elaboraram um etograma, ou seja, por meio de um levantamento dos prováveis comportamentos a serem observados (descritos preliminarmente em um guia de campo) foi feito um inventário/quantificação através de metodologias de observação. A finalidade foi obter uma relação dos comportamentos mais observados e em quais metodologias escolhidas; para, então, propor a metodologia de observação mais indicada para desenvolvimento de atividades turísticas.

Para a atividade desenvolvida no Parque Estadual da Ilha do Cardoso, foram 
Atividades de observação do comportamento de Sotalia guianensis como subsídio para o Turismo Científico no Parque Estadual Ilha do Cardoso - Cananeia (SP).

escolhidas cinco metodolodias, sendo a primeira delas o scan ou focal. Para tal formou-se quatro subgrupos de observação, com cerca de cinco pessoas, postados em quatro pontos da praia de modo a terem entre si uma mesma distância. $A$ atividade consistia em observar o mar através de um ponto fixo na praia, tendo os integrantes do grupo binóculo de observação a longa distância. Os comportamentos eram quantificados durante o período de uma hora.

Decorrido este período, os subgrupos deveriam migrar para um dos quatro pontos pré-determinados. Durante este deslocamento era realizada a segunda metodologia de observação, conhecida como transecto com estilo específico, na qual o grupo anotava todos os comportamentos observados no decorrer da caminhada pela praia.

Enquanto os subgrupos migravam de um ponto ao outro, o orientador da atividade realizava o transecto dentro da água, estando a altura do joelho, para que fosse observada interferência humana nos comportamentos, quando em deslocamento. O percurso percorrido foi a totalidade da orla de observação destinada, a praia do Núcleo Perequê.

Quando já no segundo ponto de observação, os grupos realizaram a metodologia conhecida como registro temporal binário, realizada da seguinte forma: o subgrupo permanecia 10 minutos na areia, sem anotar qualquer tipo de comportamento observado no mar e, então, 5 minutos dentro do mar com a água na altura da cintura, anotando os comportamentos observados durante esse período. Foram realizadas 6 repetições desta atividade, totalizando uma hora e meia de observação.

A última atividade de observação consistia na metodologia de formação de barreira na água, realizada com o grupo todo, composto por cerca de 20 estudantes, formando um semi-círculo na água, tendo a maioria dos integrantes água na altura da cintura. Esta atividade teve duração de uma hora, visando observar também a influência da presença humana nos comportamentos da espécie.

Ao final das cinco metodologias, os comportamentos listados por todos os subgrupos comporam um etograma qualitativo dos comportamentos observados.

\section{Resultados e Discussão}

As atividades de scan ou focal puderam registrar diferentes tipos de comportamentos, sendo o principal registro os comportamentos de vários tipos de deslocamento (Fig. 2) e de pesca, uma vez que é conhecido em literatura que está espécie busca a pesca com barreira física e a área de observação era em uma praia de tombo com cercos-fixos presentes em alguns lugares (Fig. 3). No entanto, 0 discernimento entre os tipos de comportamento de deslocamento e pesca feitos devem levar em conta a falta de prática dos alunos envolvidos na atividade, indicando que um estudo mais detalhado, com mais horas em campo, poderia gerar dados mais precisos. 


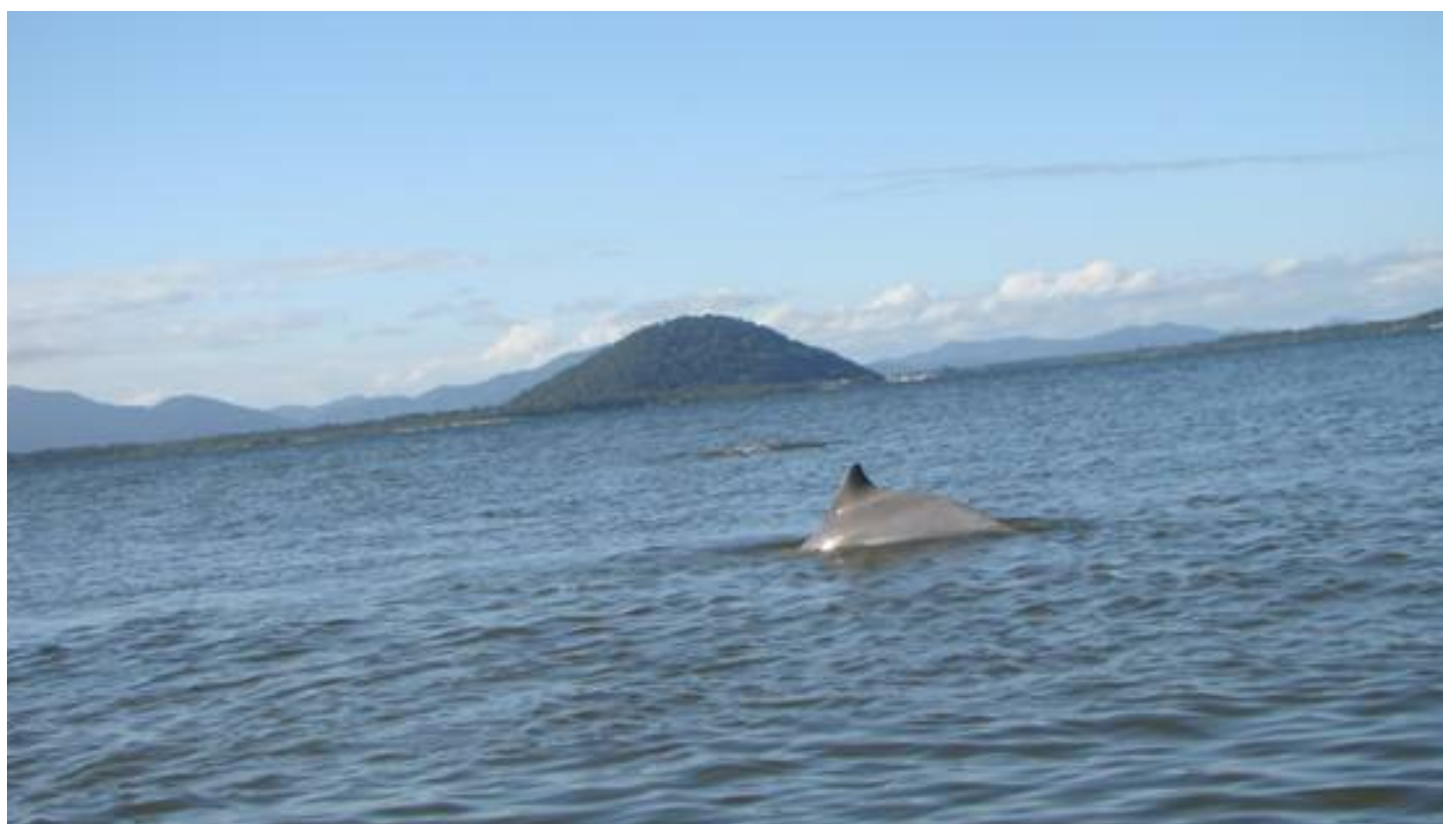

Figura 2 - Boto cinza realizando o comportamento de deslocamento em velocidade média, pode-se concluir que o boto está realizando um deslocamento em velocidade média pelo ângulo da curvatura do corpo quando passa pela superfície que é ligeiramente agudo. Foto: SCHILINDWEIN, M. N.

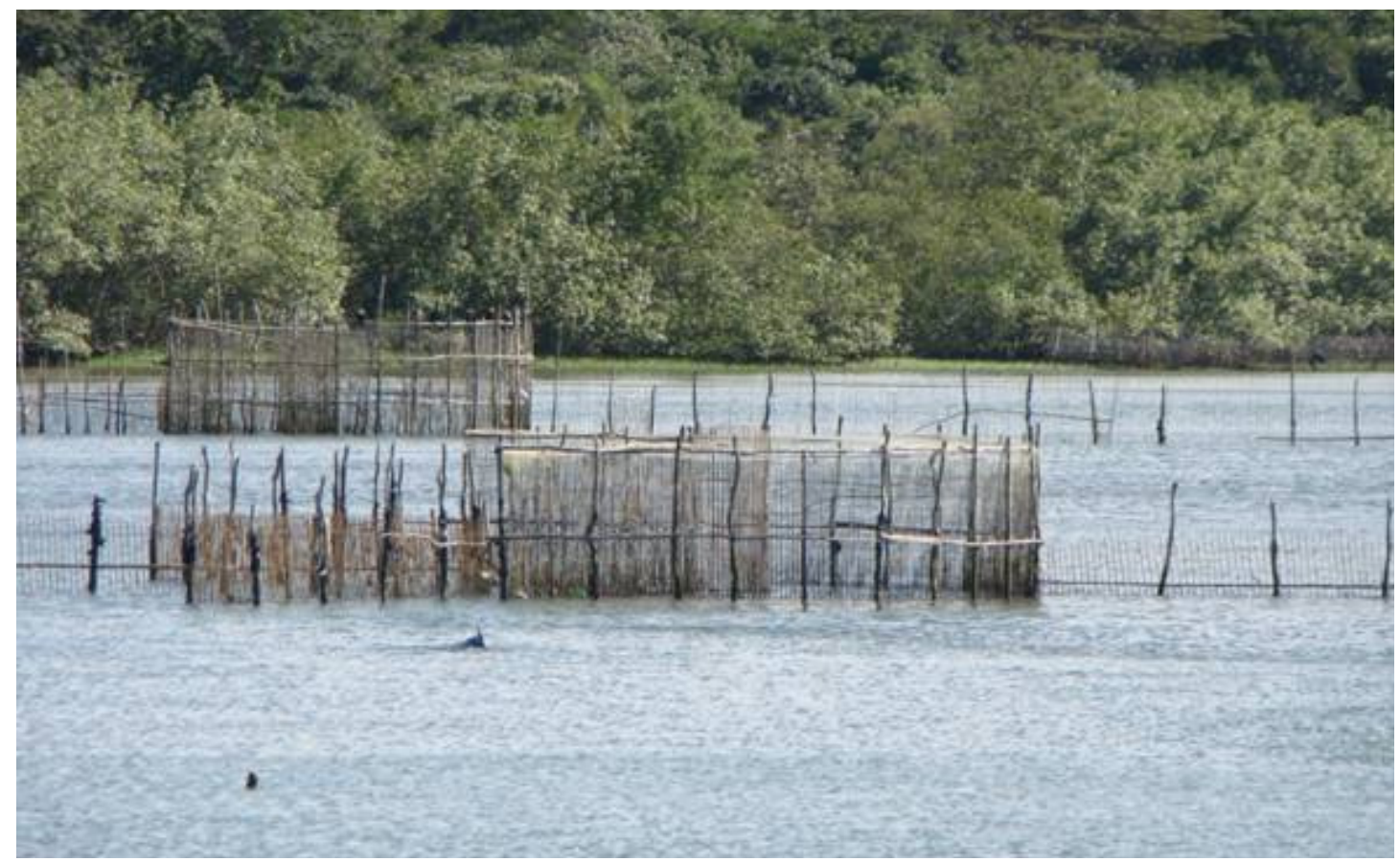

Figura 3 - Presença de um boto próximo ao cerco-fixo, provavelmente realizando a atividade de pesca. Foto: SCHILINDWEIN, M. N. 
Atividades de observação do comportamento de Sotalia guianensis como subsídio para o Turismo Científico no Parque Estadual Ilha do Cardoso - Cananeia (SP).

Apesar disso, diferentes tipos de deslocamento foram observados, além da prática de pesca com barreiras, na qual grupo cercou um cardume, conduzindo-o à praia do tombo, onde outros membros do grupo aguardavam para preda-los. Nessa atividade também pode-se observar o envolvimento de gaivotas. Estas tem interação mutualística com os golfinhos, uma vez que, as gaivotas indicam aos golfinhos onde se encontram o cardume e esses beneficiam as gaivotas cercando o cardume.

Além disso, foram observados comportamentos considerados raros, como a exposição do ventre de um golfinho e as nadadeiras laterais, eventos que provavelmente estão envolvidos em brincadeiras, assim como diferentes tipos de saltos e cambalhotas, que também foram observados.

Alguns tipos de salto podem não somente estar envolvidos com brincadeiras, mas tendo um sentido de buscar reconhecer o ambiente e ainda podem fazer parte da atividade de pesca, como quando um golfinho tira todo seu corpo de dentro da água ou bate a nadadeira na água, esse recurso pode ser utilizado para atordoar sua presa, tornando a pesca mais fácil. Considerando que no período de observação havia cardumes de peixes e que a atividade de pesca foi observada, presume-se que estes saltos com batida de corpo inteiro ou nadadeiras na água podem servir a esse propósito também.

Ainda pode ser visto nessa metodologia comportamentos de reconhecimento, no qual um golfinho emergia a cabeça da água, expondo os olhos com o intuito de buscar reconhecer seus observadores.

A segunda metodologia, transecto com estilo específico, apresentou apenas registros de comportamento de deslocamento ou alguns saltos. A baixa descrição de comportamentos observados pode ser explicada pela atividade de pesca, que os golfinhos desenvolviam no lado esquerdo da orla, ou pelo fato da metodologia mais indicada de observação realmente consista na escolha de um ponto de observação fixo, ou quando em movimento quando for observado o deslocamento de todo o bando para algum outro ponto da praia.

A metodologia empregada pelo observador da atividade, transecto dentro da água, que visava essencialmente prever mudanças de comportamento pela presença antrópica, demonstrou que os espécimes presentes na área de estudo eram pouco influenciados pela presença humana, ou seja, a pequena atividade antrópica no decorrer do experimento, principalmente no trânsito de veículos náuticos, não interferiu no comportamento do bando. Novos estudos são necessário para avaliar quantitativa e qualitativamente este impacto nos locais e períodos de maior visitação, de modo a avaliar a interferência da influência da presença de turistas. Um procedimento importante seria estimar a capacidade de carga e mapeamento espacial e sazonal para observação destes cetáceos. Os dados destes estudos foram fundamentais na delimitação das atividades de observação nas áreas de pesca dos botos, permitindo a maximização de protocolos de observação e da maior interação do ser humano com os golfinhos sem afetar drasticamente seus comportamentos naturais.

Durante a permanência dos pesquisadores no PEIC, constatou-se, inclusive, casos de reconhecimento dos golfinhos pelos habitantes locais através de cicatrizes 
ocasionadas por redes de pesca ou hélices de barcos. Isso leva a concluir que esses golfinhos tornaram-se tão acostumados à presença humana que podem ser considerados dóceis, sendo também evidente o perigo que esse comportamento adquirido acarreta a sobrevivência desse grupo. Apesar disso, pode-se registrar comportamentos de reconhecimento e deslocamento, que podem refletir justamente a proximidade que estes botos adquiriram com os habitantes locais, sendo que a partir de um rápido reconhecimento, o golfinho que estava se deslocando parou.

Durante o registro temporal binário (Fig. 4) foram observados comportamentos semelhantes aos descritos na primeira metodologia, com nota para o fato de não ter ocorrido registros de comportamento nas primeiras idas ao mar pelo grupo de alunos, podendo ser justificada pela atividade de pesca e pelo subsequente deslocamento que 0 bando teria feito até outro lado da praia.

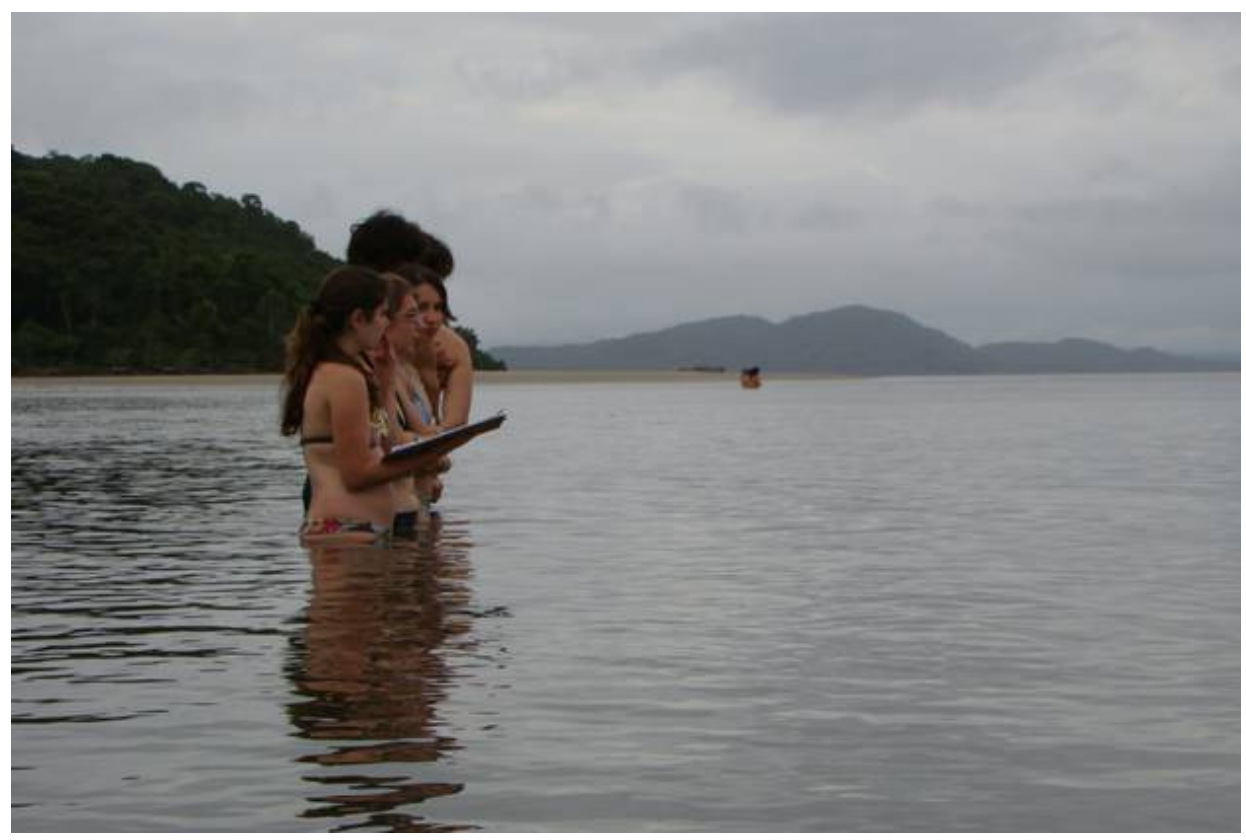

Figura 4 - Pode-se observar dois grupos de pesquisadores realizando a metodologia de registro temporal binário, um grupo no canto esquerdo da foto e outro no meio bem ao fundo. Foto: SCHILINDWEIN, M. N.

A última metodologia, formação de barreira na água (Fig. 5), mostrou-se a mais rica no que diz respeito a buscar a proximidade e maior contato entre os alunos e os botos (Fig 6). Nesta foram observados muitos comportamentos de reconhecimento e brincadeiras, como saltos; sendo que um boto pode chegar a cerca de um metro dos grupos de pesquisadores. Para fins de conservação que buscam um respaldo emotivo entre a espécie a ser conservada e os agentes de conservação, essa metodologia foi a que conseguiu alcançar um maior grau de satisfação e contentamento, garantindo uma experiência que sem dúvida marcaria a lembrança dos envolvidos, garantindo o desejo de regresso ao local. 
Atividades de observação do comportamento de Sotalia guianensis como subsídio para o Turismo Científico no Parque Estadual Ilha do Cardoso - Cananeia (SP).

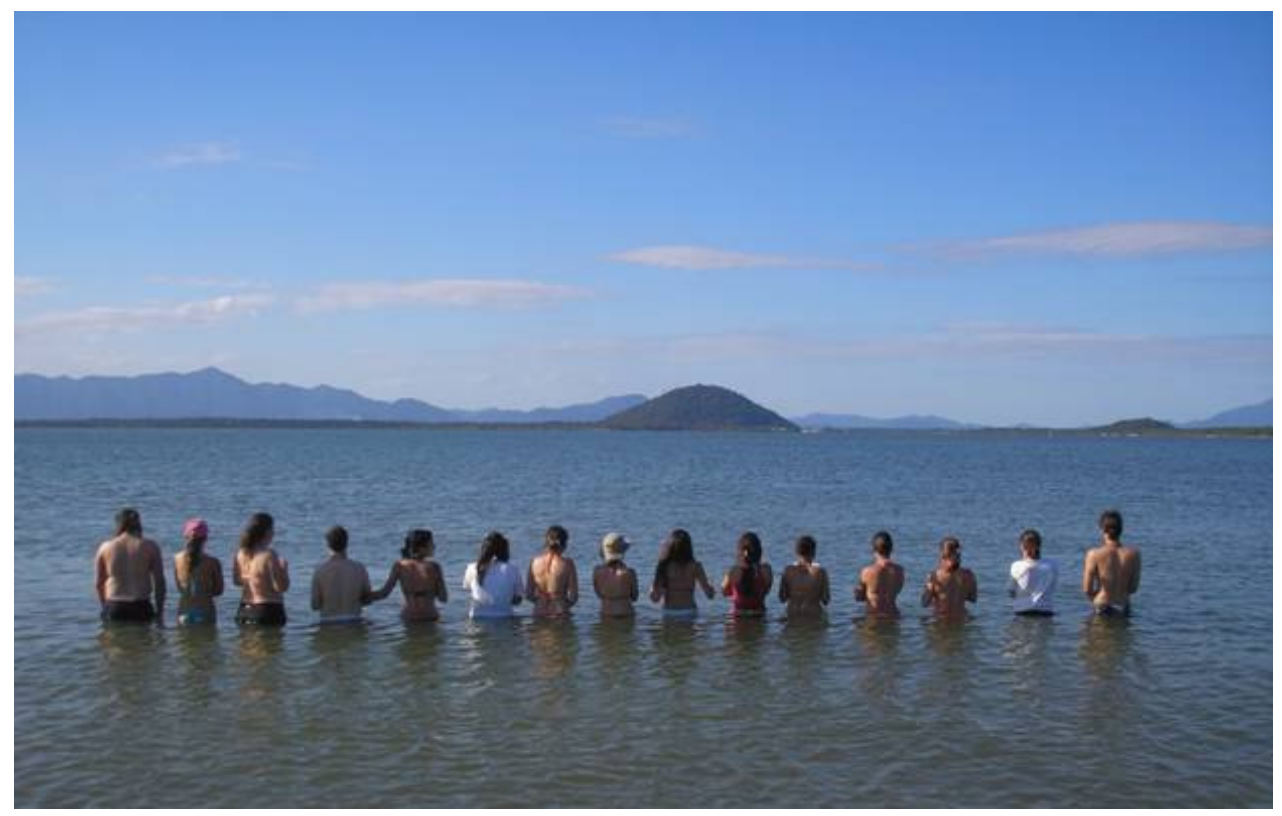

Figura 5 - Pesquisadores realizando a metodologia formação de barreira na água, proporcionando uma maior aproximação entre eles e os botos. Foto: SCHILINDWEIN, M. N.

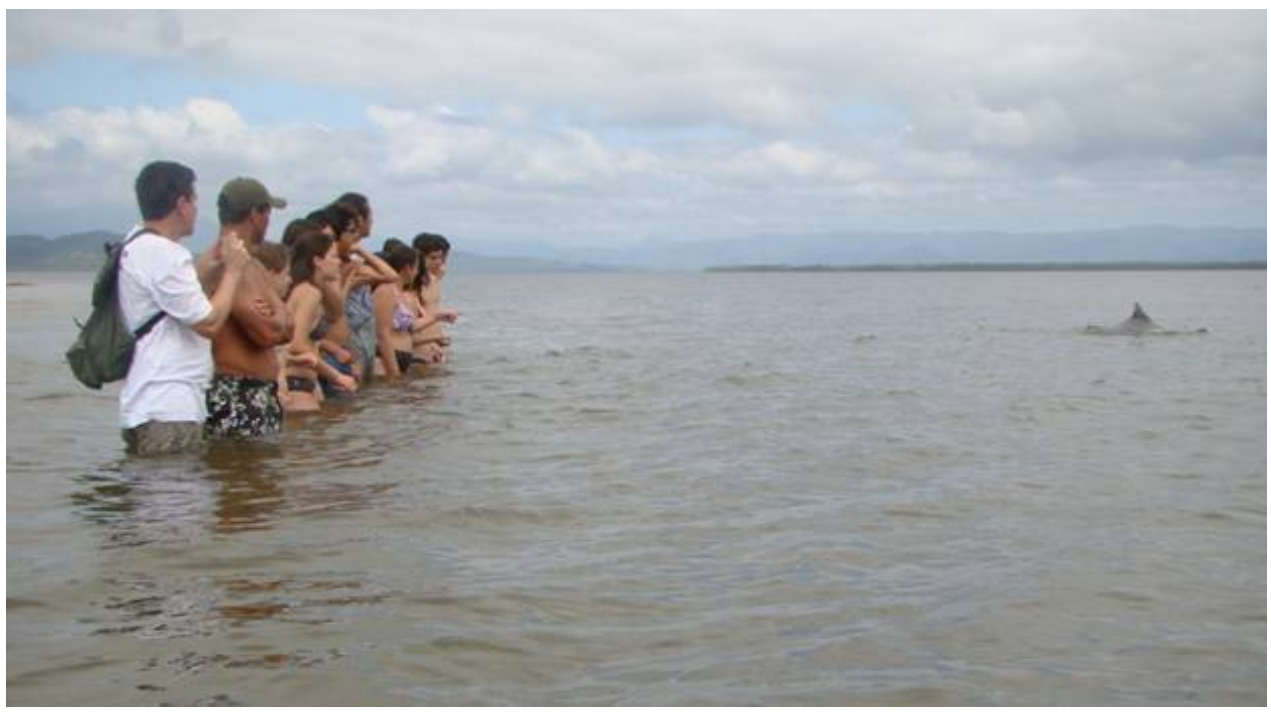

Figura 6 - Aproximação de um boto enquanto os pesquisadores realizavam a metodologia de formação de barreira na água. Foto: SCHILINDWEIN, M. N.

Assim, nosso estudo pode apontar que a melhor metodologia a ser aplicada em futuras atividades de turismo científico é a de observação com formação de barreira na água, pois a mesma possibilita uma boa variedade de comportamentos e uma maior aproximação entre a espécie a ser observada e os observadores.

A partir do emprego das metodologias descritas, defende-se aqui que a atividade de 
turismo científico por meio do estudo comportamental de $S$. guianensis demonstra a importância de um contato direto com o ambiente ao redor, em específico com espécies que têm a capacidade de se tornarem bandeiras para conservação de um local ou ecossistema, para garantir maior envolvimento e interesse em se preservar a vida como um todo.

As atividades de turismo, que desenvolvam práticas como as aqui descritas podem promover não somente uma satisfação pessoal e sentimento de bem-estar como também um conhecimento mais profundo sobre a biologia de espécies por vezes distantes do convívio da maioria da população. Essa aproximação pode não somente envolver emocionalmente, como também conscientizar os praticantes a respeito de sua relação com todo o ecossistema natural. O presente estudo, que utilizou as metodologias de observação do comportamentos do boto-cinza aqui descritas, portanto, pode servir de subsídio para elaboração de futuros roteiros ecoturísticos naquela Unidade de Conservação e em outros locais de ocorrência da espécie, envolvendo não somente os visitantes ocasionais e os guias de turismo, como também a visitação agendada por escolas tanto de ensino fundamental e médio como de nível superior.

\section{Referências Bibliográficas}

CAMPOLIM, M. B.; PARADA, I. L. S.; YAMAOKA, J. G. Gestão Participativa da Visitação Pública na Comunidade do Maruja - Parque Estadual da Ilha do Cardoso. IF Ser. Reg., São Paulo, n. 33, p. 39-43, 2008.

CREMER, M. J. Ecologia e Conservação do Golfinho Sotalia fluviatilis guianensis (Cetácea: Delphinidae) na Baía de Babitonga. Litoral Norte de Santa Catarina. 2000. $2227 f$. Dissertação (Mestrado em Ecologia e Recursos Naturais) - Universidade Federal de São Carlos, São Caros. 2000.

GIRAUDO, A. R.; POVEDANO, H. Ameaças de Extinção das Espécies-bandeira na Mata Atlântica e Interior. In: GALINDO-LEAL, C.; CÂMARA, I. G. (Ed.). Mata Atlântica: Biodiversidade, Ameaças e Perspectivas. Belo Horizonte: Conservação Internacional, 2005. Cap. 16.

HERO, J. M.; RIDGWAY, T. Declínio Global de Espécies. In: ROCHA, C. F. D. et al. Biologia da Conservação: Essências. São Carlos: RiMa, 2006. p. 53-90.

MAMEDE, S. B.; ALHO, C. J. R. Turismo de Contemplação de Mamíferos do Pantanal: alternativa para o uso sustentável da fauna. Campo Grande: UNIDERP, 2003.

MONTEIRO, M. S.; SOUTO, A.; DO NASCIMENTO, L. F. Comparações entre os Comportamentos de Forrageio nas Diferentes Faixas Etárias do Boto-cinza (Sotalia guianensis) (Cetacea; delphinidae) na Baia dos Golfinhos, Praia de Pipa, RN, Brasil. Revista de Etologia, v. 8, n. 1, p. 13-25, 2006.

MONTEIRO-FILHO, E. L. A.; MONTEIRO, L. R.; DOS REIS, S. F. Sistemática e Distribuição de Sotalia. In: MONTEIRO-FILHO, E. L. A.; MONTEIRO, K. D. K. A. (Org.). Biologia, Ecologia e Conservação do Boto-cinza. São Paulo: Páginas \& Letras Editora e Gráfica, 2008. p. 3-10.

MOTTA, M. R. A. Avaliação Macroscópica e Histopatológica de Cetáceos Encalhados no Litoral do Ceará. 2006. 130 f. Dissertação de Mestrado - Curso de Pós Graduação em Ciências Veterinárias, Universidade Estadual do Paraná, Fortaleza, 2006. 
Atividades de observação do comportamento de Sotalia guianensis como subsídio para o Turismo Científico no Parque Estadual Ilha do Cardoso - Cananeia (SP).

NARDY, O. Macroecologia de Cetáceos Marinhos (Ordem Cetácea). 2003. 101f. Dissertação de Mestrado - Instituto de Biociências, Universidade Estadual Paulista "Júlio de Mesquita Filho", Campus de Rio Claro, Rio Claro, 2003.

PALAZZO JR, J. T.; BOTH, M. C. Guia dos mamíferos do Brasil. Porto Alegre: Sagra, 1988. ROSINI, F.; FERREYROS, A. R. S. Situação Profissional dos Egressos da Primeira e Segunda Turma do Curso de Turismo da Faculdade Estácio de Sá de Ourinhos-SP. Ourinhos: FAESO, 2005.

SCARANO, F. R. Prioridades para Conservação: A Linha Tênue que Separa Teorias e Dogmas. In: ROCHA, C> F. D. et al. Biologia da Conservação: Essências. São Carlos: RiMa, 2006. p. 22-39.

SCHLINDWEIN, M. N. Fundamentos de Ecologia para o Turismo. São Carlos: Edufscar, 2009.

SOS MATA ATLÂNTICA. 2003. UC's na Área do pólo Lagamar. Disponível em:<http:// wwwsosribeira.org.br/institucional/regiao/uc_lista.htm>. Acesso em: 17 de mai. 2010.

SOUZA, P. C. Imunoexpressões pulmonar e esplênica das citocinas IL-12, TGF- $\beta$ e TNF- $\alpha$ e das proteínas Lizozima e S-100 em Pontoporia blainvillei (Gervais e d'Orbigny, 1844) (Mammalia, Cetácea). 2010. 109 f. Dissertação de Mestrado - Programa de Pós Graduação em Patologia Experimental Comparada da faculdade de Medicina Vetrinária e Zootecnia, Universidade de São Paulo, 2010.

VELOSO, M. Turismo acadêmico: uma nova segmentação. Brasília: UNB, 2003.

WIECZOREK, A. Mapeamento de Sensibilidade a Derramento de Petróleo do Parque Estadual da Ilha do Cardoso - PEIC e Áreas do Entorno. 2006. 157f. Dissertação de Mestrado. Instituto de Geociências e Ciências Exatas, Universidade Estadual Paulista Júlio de Mesquita Filho, Campus de Rio Claro. Rio Claro. 2006.

Marcelo Nivert Schlindwein: Universidade Federal de São Carlos

Email: mnivert@ufscar.br

Link para currículo Lattes: http://lattes.cnpq.br/9690898537150950

Andréia Tami Akaki: Universidade Federal de São Carlos

Email: deia.bioufscar@gmail.com

Link para currículo Lattes: http://lattes.cnpq.br/0336731324418074

Natasha Marcili Laganaro: Universidade Federal de São Carlos

Email: suu.nana@gmail.com

Link para currículo Lattes: http://lattes.cnpq.br/4338144104225926

Data de submissão: 03 de dezembro de 2010.

Data do aceite: 04 de abril de 2011. 